\title{
Plantar Cornu Cutaneum Associated with Cutaneous Myxoma
}

\author{
Olugbenga Ojo Oludiran ${ }^{1}$, Victor James Ekanem², Phillip Felix Umebese ${ }^{3}$ \\ ${ }^{1,3}$ Department of Orthopaedics and Traumatology \\ ${ }^{2}$ Department of Morbid Anatomy \\ College of Medical Sciences, University of Benin, Benin, Nigeria \\ E-mail: oludiran@yahoo.com \\ Received June 1, 2010; revised September 30, 2010; accepted October 10, 2010
}

\begin{abstract}
Cutaneous horns are rare in black patients probably as a result of the rarity of sun induced associated skin lesions. However reports of these lesions are filtering in from Africa. In this paper we report an unusual case on the sole of the foot in a native African from Nigeria. This is probably the first documentation of the lesion on the sole of the foot in the world literature.
\end{abstract}

Keywords: Horn, Cutaneous Horn, Cornu Cutaneum

\section{Introduction}

Cutaneous horns or cornu cutaneum as they are sometimes called have been object of curiosity both to the medical and lay world. The name derives from the resemblance to animal horns from which it differs in not having a bony core $[1,2]$. From the earliest documented case in 1588 there have been several cases reported. However most of the reports were in the light skinned races because of its association with sun exposure and actinic keratoses. Over $30 \%$ of cases are seen in the head and neck region [3]. There have been reports on occurrence in unusual locations such as the lacrimal sac [2], nasal vestibule [4], glans penis [5-7] and the lower lip [8]. Little attention has been paid to this morphologic entity in the African races with a report [3] from East Africa in 2007 appearing as probably the first. This occurred on the scalp following chronic burn scarring. An earlier report on this condition from Sudan was in an Arab [3].

This report is presented to document the first case in a Nigerian woman occurring in the sole of the foot.

\section{Case History}

A 54 year old Nigerian woman presented to the Plastic Surgery clinic of the University of Benin Teaching Hospital, Benin City, with a recurrent painful growth on the sole of the left foot of three years duration. The pain predated the growth by two weeks, was intermittent, worse with walking barefooted and relieved with hot compresses. The growth was hard and progressively increased in size in spite of antibiotic medications. She had a surgical excision a year later at the Military Hospital in Benin but had a recurrence within a few weeks. She had no diagnosed premorbid condition. She had no known allergy and neither smoked nor used alcohol. On examination, She was an otherwise healthy looking woman who was not pale. Her cardiovascular system was normal with BP 120/80. She had a horny growth $40 \mathrm{~mm}$ long on the sole of the hind foot the shape of a twisted cone deviating medially. The diameter at the base was 30 $\mathrm{mm}$ (Figure 1). It was not tender and the surrounding skin appeared normal. The sensation in the surrounding skin was normal (touch and pin prick), and peripheral circulation was adequate. Regional nodes were not enlarged. A gross clinical assessment of a cutaneous horn was made and she was scheduled for an excision biopsy. Her preoperative hematocrit was $9.7 \mathrm{~g} / \mathrm{dl}$ and blood sugar was normal. She had surgical excision with $2 \mathrm{~cm}$ rim of normal skin at the margins under local anaesthesia. The growth was entirely cutaneous, not extending into the subcutaneous tissue. The surgical defect was resurfaced with a full thickness skin graft from the groin retained with a bolus dressing. The post operative course was uneventful with satisfactory wound healing (Figure 2). She was discharged on the $10^{\text {th }}$ postoperative day and has been followed up in the outpatient clinic.

Histology showed markedly hyperkeratotic and acanthotic epidermis with prominent rete pegs. Beneath the epidermis is prominent mucinous matrix in which there 


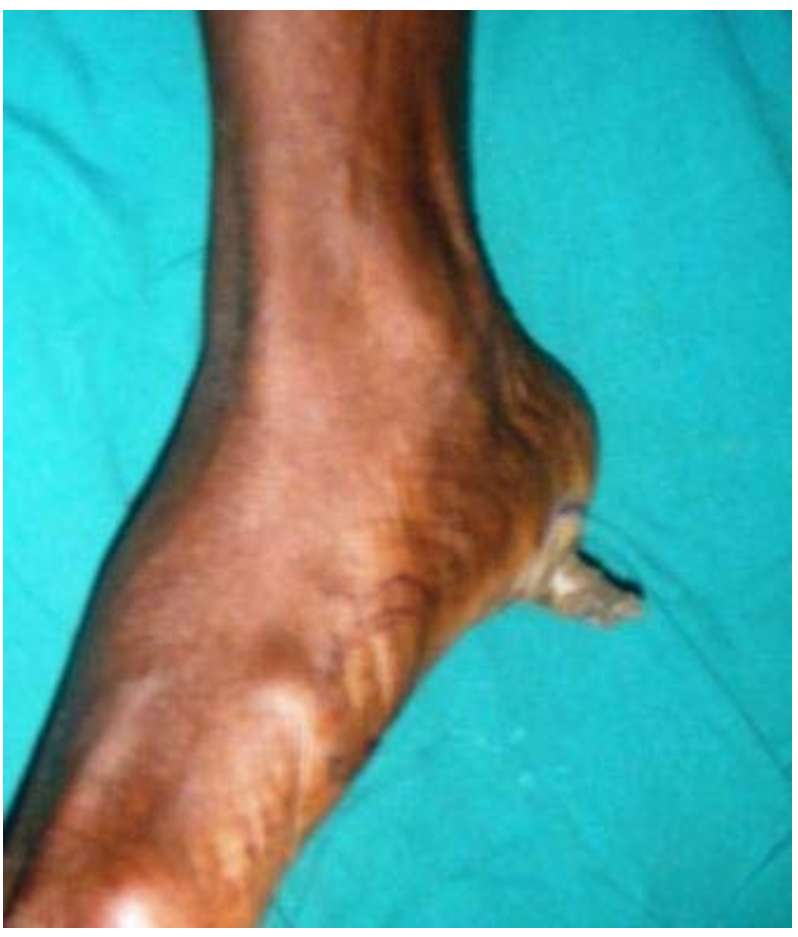

Figure 1. Cutaneous horn on the sole of the foot.

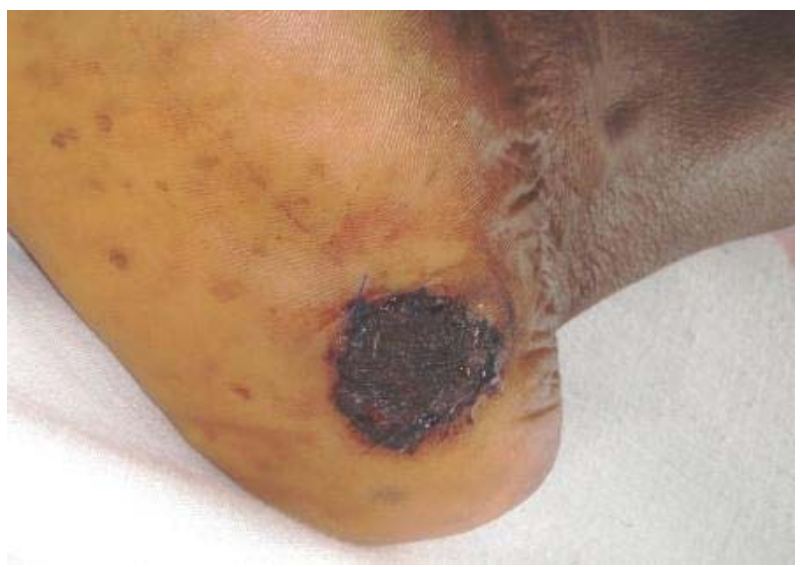

Figure 2. The same foot after excision and full thickness skin grafting.

are variably shaped fibroblasts, thin collagen bundles and thin capillaries (Figure 3 and 4).

\section{Discussion}

Reported cutaneous horns appear uncommon in the black races but are by no means unheard of. The corresponding author recalls childhood folklore often told, of a certain "Alade" who grew a horn on his head. It is however unknown whether that was real or just a myth. Poor utilization of orthodox medical facility, inadequate documentation and lack of reporting are issues that contribute to the perception of rarity of certain medical entities in our population. With increasing urbanization and improved medical record keeping increasing number of hitherto conceived rare conditions will be reported.

Cutaneous horns have been described in many parts of the body [1-8]. A search of the literature however would suggest this to be the first from the sole of the foot. Although sun exposure has been touted to be the major risk factor, this would not appear to be the cause in this case. Chronic irritation as occurs from the repeated trauma of walking bare footed could be responsible. This is similar to the clinical history of malignant melanoma which is more common on the sole of the foot in our population.

Although the aetiology is not very clear, its morbid anatomy has been well described. It consists essentially of dead cornified cutaneous excrescence organized in the shape of a horn displaying hyperkeratosis, acanthosis,

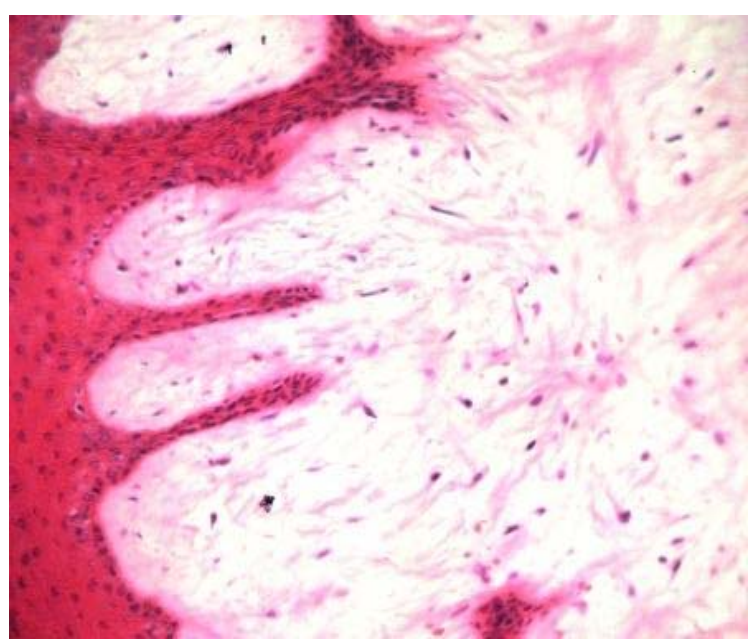

Figure 3. Histological section of the cutaneous horn showing prominent rete pegs, thin collagen bundles and fibroblast within the mucinous matrix.

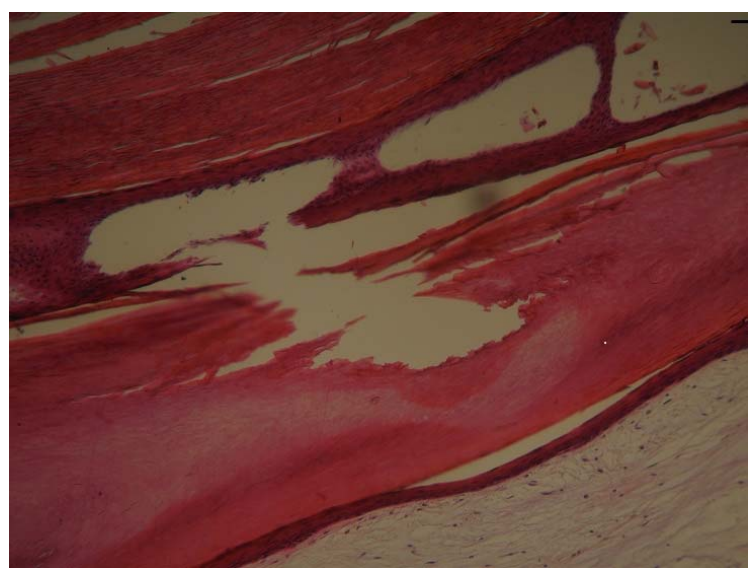

Figure 4. A section of the cutaneous horn showing hyperkeratosis, acanthosis and myxoid stroma. 
dyskeratosis, papillomatosis and inflammatory infiltration of adjacent dermis [1,5]. These may be superimposed on pathologic features of an underlying associated disease.

Cutaneous horns have been associated with a wide variety of clinical conditions, benign, premalignant and malignant. These include actinic keratosis, seborrheic keratosis, keratoacanthoma, haemangioma, keratotic pseudopapillomatous balanitis, sebaceous adenoma, verruca vulgaris, trichilemma, histiocytoma, molluscum contagiosum, grannular cell tumour, Bowen's disease, Paget's disease of the breast, basal cell carcinoma squamous cell carcinoma, malignant melanoma and Kaposi sarcoma [1,10,11]. It has also been associated with cutaneous spread of malignancies as was reported by Rajeev and colleagues in association with renal cell carcinoma [8]. In our patient the cutaneous horn is associated with a myxoma. Thus it is essential to look beyond the horn in planning the management. Large size, rapid growth and tenderness at the base have been associated with malignancy [1,5]. In this case, a wide excision with a $2 \mathrm{~cm}$ margin was carried out for adequate oncological clearance in case of possible malignancy. The specimen was evaluated histologically for pathological diagnosis and microscopic evaluation of the margin of resection. Other treatment options include excision and direct wound closure where feasible, electrocautery, cryosurgery, and laser ablation of the base after removal of the horn [12]. Recurrence following a previous excision, at another centre, in this patient is probably from inadeqaute excision. However recurrences like this has been noted to occur. This report documents, perhaps for the first time, a cutaneous horn on the sole of the foot of a black African.

\section{Reference}

[1] E. Copcu, N. Sivrioglu, N. Culhaci, "Cutaneous Horns: Are These Lesions as Innocent as They Seem to be?”
World Journal of Surgical Oncology, Vol. 2, No. 18, 2004.

[2] G. R. Murthy, "Cutaneous Horn in the Lacrimal Sac Region - A Case Report,” Indian Journal of Ophthalmology, 1969, Vol. 17, No. 4, pp. 154-155.

[3] P.M. Nthumba, "Giant Cutaneous Horn in an African Woman - A Case Report,” Journal of Medical Case Report. 2007; 1:170. doi:10.1186/1752-1947-1-170

[4] E. Yanagisawa and K. Yanagisawa, "Cutaneous Horn of the Nasal Vestibule,” Ear Nose Throat Journal, Vol. 80, No. 11, 2001, pp. 780.

[5] A. Rekha and A. Ravi, "Cornu Cutaneum - Cutaneous Horn on the Penis,” Indian Journal of Surgery, Vol. 66, No. 5, 2004, pp. 296-297.

[6] R. Nayyar, P. Singh and A. Seith, "Penile Cutaneous Horn over Long Standing Radiation Dermatitis,” Journal of Postgraduate Medicine, Vol. 55, No. 4, 2009, pp. 287. doi:10.4103/0022-3859.58937

[7] G. A. Solivan, K. J. Smith and W. D. James, “Cutaneous Horn on the Penis: Its Association with Squamous Cell Carcinoma and HPV-16 Infection,” Journal of the American Academy of Dermatology, Vol. 23, No. 5, 1990, pp. 969-972. doi:10.1016/0190-9622(90)70315-9

[8] T. P. Rajeev, L. N. Dorairajan and A. K. Hemal, "Chest Horn: An Unusual Metastasis from Renal Cell Carcinoma,” Indian Journal of Urology, Vol. 17, No. 2, 2001, pp. 174-175.

[9] M. Mutaf, “A Rare Perioral Lesion: Cutaneous Horn of the Lower Lip,” European Journal of Plastic Surgery. Vol. 29, No. 7, 2007, pp. 339-41. doi:10.1007/s00238-006-0101-y

[10] D. Krzysztof and L. S., "Howard Paget's Disease of the Breast Presenting as a Cutaneous Horn,” Journal of Surgical Oncology, Vol. 29, No. 4, 2006, pp. 237-239.

[11] J. W. Gould and R. T. Brodell, "Giant Cutaneous Horn Associated with Verruca Vulgaris,” Cutis, Vol. 64, No. 2, 1999, pp. 111-112.

[12] F. C. Lowe and A. R. McCullough, "Cutaneous Horn of the Penis- An Approach to Management. Case Report and Review of the Literature," Journal of the American Academy of Dermatology, Vol. 13, No. 2, 1985, pp. 369 -373. doi:10.1016/S0190-9622(85)70177-6 